\title{
Ginsenoside Rg3 induces DNA damage in human osteosarcoma cells and reduces MNNG-induced DNA damage and apoptosis in normal human cells
}

\author{
YUE-HUI ZHANG $^{1 *}$, HAI-DONG LI ${ }^{1,2^{*}}$, BO LI $^{1}$, SHENG-DAN JIANG $^{1}$ and LEI-SHENG JIANG ${ }^{1}$ \\ ${ }^{1}$ Department of Orthopedic Surgery, Xinhua Hospital, Shanghai Jiaotong University School of Medicine, Shanghai 200092; \\ ${ }^{2}$ Department of Orthopedic Surgery, First People's Hospital, Huzhou Normal Institute, Zhejiang 313000, P.R. China
}

Received October 25, 2013; Accepted November 21, 2013

DOI: $10.3892 /$ or.2013.2914

\begin{abstract}
Panax ginseng is a Chinese medicinal herb. Ginsenosides are the main bioactive components of $P$. ginseng, and ginsenoside $\operatorname{Rg} 3$ is the primary ginsenoside. Ginsenosides can potently kill various types of cancer cells. The present study was designed to evaluate the potential genotoxicity of ginsenoside $\operatorname{Rg} 3$ in human osteosarcoma cells and the protective effect of ginsenoside $\mathrm{Rg} 3$ with respect to $\mathrm{N}$-methyl$N$ '-nitro- $N$-nitrosoguanidine (MNNG)-induced DNA damage and apoptosis in a normal human cell line (human fibroblasts). Four human osteosarcoma cell lines (MG-63, OS732, U-2OS and HOS cells) and a normal human cell line (human fibroblasts) were employed to investigate the cytotoxicity of ginsenosides Rg3 by MTT assay. Alkaline comet assay and $\gamma \mathrm{H} 2 \mathrm{AX}$ focus staining were used to detect the DNA damage in MG-63 and U-2OS cells. The extent of cell apoptosis was determined by flow cytometry and a DNA ladder assay. Our results demonstrated that the cytotoxicity of ginsenoside Rg3 was dose-dependent in the human osteosarcoma cell lines, and MG-63 and U-2OS cells were the most sensitive to ginsenoside $\mathrm{Rg} 3$. As expected, compared to the negative control, ginsenoside $\mathrm{Rg} 3$ significantly increased DNA damage in a concentration-dependent manner. In agreement with the comet assay data, the percentage of $\gamma \mathrm{H} 2 \mathrm{AX}$-positive MG-63 and U-2OS cells indicated that ginsenoside $\mathrm{Rg} 3$ induced DNA double-strand breaks in a concentration-dependent manner. The results also suggest that ginsenoside $\mathrm{Rg} 3$ reduces the extent of MNNG-induced DNA damage and apoptosis in human fibroblasts.
\end{abstract}

Correspondence to: Professor Lei-Sheng Jiang, Department of Orthopedic Surgery, Xinhua Hospital, Shanghai Jiaotong University School of Medicine, 1665 Kongjiang Road, Shanghai 200092, P.R. China

E-mai: jiangleisheng@126.com

\section{${ }^{*}$ Contributed equally}

Key words: ginsenoside Rg3, DNA damage, apoptosis, alkaline comet assay, $\gamma \mathrm{H} 2 \mathrm{AX}$ foci, DNA fragmentation

\section{Introduction}

Osteosarcoma is a malignant bone tumor that usually develops in adolescents and young adults. The National Cancer Institute estimates the number of new cases of osteosarcoma each year to be 4.4 per one million among individuals aged $0-24$ years (1). Most treatment protocols for osteosarcoma use an initial period of systemic chemotherapy prior to definitive resection of the primary tumor. Notably, most of the commonly used chemotherapeutic drugs kill normal as well as cancer cells (2). Therefore, drugs targeted specifically at cancer cells while leaving normal cells intact, or even protecting normal cells, would be ideal for use as part of a chemotherapy regimen.

Panax ginseng was discovered over 5,000 years ago in the hills of Manchuria in China. Since then, the plant has held its place as a highly venerated medicinal plant in traditional Chinese medicine (3). Over recent decades, the anticancer effects of ginsenosides have garnered increasing attention because of their favorable safety and efficacy profiles (4). Ginsenosides enhance cytotoxic and humoral immune responses (5). Recent research has shown that ginsenosides can inhibit the growth of several cancer cell lines (6). The anticarcinogenic and antimetastatic effects of ginsenoside $\mathrm{Rg} 3$ have been demonstrated in vitro and in vivo (7). Ginsenoside $\mathrm{Rg} 3$ induces cell cycle arrest and apoptosis in mammalian tumor cells (8). However, few published reports describe the genotoxicity of ginsenoside $\mathrm{Rg} 3$. In contrast, the cytoprotective effect of ginsenosides has been demonstrated in other studies. Poon et al (9) showed that ginsenoside 20-Rg3 protected against BaP-induced DNA damage in human dermal fibroblasts (HDFs). Ginsenoside Rg3 was found to protect against cyclophosphamide-induced DNA damage and cell apoptosis by reducing oxidative stress (10). Ginseng extract was also found to protect against $\gamma$-ray-induced DNA double-strand breaks (11).

The results outlined above suggest that ginsenosides could be used for the chemotherapeutic treatment of patients with osteosarcomas. Theoretically, ginsenosides would destroy cancer cells but leave normal cells unharmed. To prove our hypothesis, we explored the effects of ginsenoside $\operatorname{Rg} 3$ on in vitro DNA damage and apoptosis in human osteosarcoma cell lines. The presumed cytoprotective effect of ginsenoside 
$\mathrm{Rg} 3$ was investigated in human fibroblasts. Sensitive and quantitative detection assays (e.g., the alkaline comet assay, measurements of $\gamma \mathrm{H} 2 \mathrm{AX}$ focus formation, flow cytometry and DNA ladder assay) were used. The results confirmed that ginsenoside Rg3 exhibited obvious genotoxicity against human osteosarcoma cells and protected normal human cells against MNNG-induced DNA damage and apoptosis.

\section{Materials and methods}

Chemicals and reagents. Ginsenoside Rg3 (purity, >96\%) was purchased from Tianping Pharmaceutical Co., Shanghai, China. The compound was dissolved in dimethyl sulfoxide (DMSO). $N$-methyl- $N$ '-nitro- $N$-nitrosoguanidine (MNNG), trypan blue, low-melting agarose (LMA), normal-melting agarose (NMA), 2-amino-2-(hydroxymethyl)-1,3-propanediol (Tris), sodium dodecyl sulfate (SDS), ethylenediaminetetraacetic acid (EDTA), 4',6-diamidino-2-phenylindole (DAPI), 3-(4,5-dimethylthiazol-2-yl)-2,5-diphenyltetrazolium bromide (MTT), Tween-20 and paraformaldehyde were obtained from Sigma Chemical Co. (Silicon Valley, CA, USA). An apoptosis detection kit was obtained from BD Pharmingen. Triton X-100, ethidium bromide (EtBr), fetal bovine serum (FBS), xylene cyanol, and bromphenol blue were obtained from Sangon Biotech Shanghai Co., Ltd. (Shanghai, China). Propidium iodide (PI) and Dulbecco's modified Eagle's medium (DMEM) were obtained from Gibco (Grand Island, NY, USA). Other common chemicals were purchased from Sinopharm Chemical Reagent Co., Ltd. (Shanghai, China).

Cell culture. The human osteosarcoma MG-63, OS732, U-2OS and HOS cell lines and human fibroblasts were purchased from the Cell Bank of the Type Culture Collection of the Chinese Academy of Sciences (Shanghai, China). The cells were cultured in DMEM supplemented with $10 \%$ heat-inactivated FBS, penicillin $(100 \mathrm{U} / \mathrm{ml})$ and streptomycin $(100 \mathrm{U} / \mathrm{ml})$. Cells were incubated at $37^{\circ} \mathrm{C}$ in a $5 \% \mathrm{CO}_{2}$ incubator. The medium was exchanged once every 2 days. After treatment, the cells were harvested by trypsinization.

Cell viability test. Cytotoxicity was measured using the MTT assay (12). The trypan blue dye exclusion assay was performed to confirm and verify cell viability. The human osteosarcoma cells and fibroblasts were seeded at a density of $1 \times 10^{4}$ cells/well in $100 \mu \mathrm{l}$ of the cell culture medium, and then placed into a 96-well plate. After $12 \mathrm{~h}$ of incubation, the cells were treated with $0-300 \mu \mathrm{M}$ ginsenoside $\mathrm{Rg} 3$ for $24 \mathrm{~h}$. Then, MTT solution ( $5 \mathrm{mg} / \mathrm{ml}$ ) was added to each well, and the samples were incubated at $37^{\circ} \mathrm{C}$ for $4 \mathrm{~h}$. Thereafter, the supernatant was removed and replaced with $100 \mu \mathrm{l}$ of DMSO. Optical density (OD) of the control and drug-treated wells was measured using an automated microplate reader (Multiskan EX; Lab Systems, Vantaa, Finland) at a test wavelength of $570 \mathrm{~nm}$.

Alkaline comet assay. The alkaline comet assay was performed according to the procedure described by CalderonSegura et al (13), with slight modifications for the evaluation of DNA single-strand breaks (SSBs). Cells were cultured in each well of a $24-w e l l$ plate, at a density of $1 \times 10^{5} / \mathrm{ml}$. Then,
MG-63 and U-2OS cells were treated with 0, 25, 50, 100 and $150 \mu \mathrm{M}$ ginsenoside $\mathrm{Rg} 3$ for $24 \mathrm{~h}$. The cells treated by MNNG $(20 \mu \mathrm{M})$ were used as the positive control and the cells treated by $0 \mu \mathrm{M}$ ginsenoside $\mathrm{Rg} 3$ were used as the negative control in the genotoxicity study. Human fibroblasts were treated with ginsenoside $\operatorname{Rg} 3(50 \mathrm{mM})$ and MNNG (20 mM) for $24 \mathrm{~h}$. Then, cells were collected, washed, and suspended in PBS ( $\mathrm{pH} 7.4) ; 30-\mu \mathrm{l}$ cell samples $\left(1 \times 10^{4}\right.$ cells) were used and suspended in $110 \mu \mathrm{l}$ of $1 \%$ molten LMA at $37^{\circ} \mathrm{C}$. The monosuspension was cast on a microscopic slide covered with a layer of $0.8 \%$ NMA. The agarose was gelled at $4^{\circ} \mathrm{C}$, after which the slides were immersed in a fresh lysis solution $(2.5 \mathrm{M} \mathrm{NaCl}$, $100 \mathrm{mM}$ EDTA, $10 \mathrm{mM}$ Tris- $\mathrm{HCl}, 1 \%$ Triton $\mathrm{X}-100,10 \%$ DMSO and $\mathrm{pH} 10.0$ ) for $30 \mathrm{~min}$ at $4^{\circ} \mathrm{C}$. After lysis, the slides were washed in distilled water three times and immersed in fresh alkaline electrophoresis solution $(300 \mathrm{mM} \mathrm{NaOH}, 1 \mathrm{mM}$ EDTA, pH 13.0) for $10 \mathrm{~min}$ at $4^{\circ} \mathrm{C}$. An electric field was then applied at $20 \mathrm{~V}(1 \mathrm{~V} / \mathrm{cm})$ and $300 \mathrm{~mA}$ for $10 \mathrm{~min}$. The slides were neutralized to $\mathrm{pH} 7.5$ in $0.4 \mathrm{mM}$ Tris buffer and stained with $40 \mu \mathrm{l}$ of $20 \mu \mathrm{g} / \mathrm{ml}$ EB. The signal emitted was analyzed using an Olympus BX53 fluorescence microscope (Olympus, Tokyo, Japan) with a 515- to 560-nm filter. The extent of DNA migration was determined using an image analysis system (CASP, www.casp.of.pl). Parameters such as tail length (DNA migration from the nucleus), tail DNA (DNA content in the tail), and the tail moment (migrated DNA in the tail multiplied by the tail length) were recorded.

$\gamma H 2 A X$ focus staining. The phosphorylation of histone H2AX was used as a marker of DNA double-strand breaks with slight modifications (14). MG-63 and U-2OS cells $\left(1 \times 10^{5}\right)$ were seeded onto 6-well culture plates and treated with 0,25 , 50 and $100 \mu \mathrm{M}$ of ginsenoside $\mathrm{Rg} 3$ and $20 \mu \mathrm{M}$ MNNG for $24 \mathrm{~h}$. Human fibroblasts were treated with ginsenoside $\mathrm{Rg} 3$ $(50 \mathrm{mM})$ and MNNG $(20 \mathrm{mM})$ for $24 \mathrm{~h}$. After treatment, the cells were fixed in $4 \%$ paraformaldehyde for $15 \mathrm{~min}$, washed with PBST (PBS buffer pH 7.4 and $0.1 \%$ Tween-20), and permeabilized in $1 \%$ Triton X-100 for $30 \mathrm{~min}$. After blocking the cells with serum for $60 \mathrm{~min}$, the samples were incubated with a rabbit monoclonal anti- $\gamma \mathrm{H} 2 \mathrm{AX}$ antibody (1:1,500; Cell Signaling Technology) overnight at $4^{\circ} \mathrm{C}$, and then incubated with an Alexa594-conjugated anti-rabbit secondary antibody (1:360; Cell Signaling Technology) for $60 \mathrm{~min}$. To stain the nuclei, cells were incubated in DAPI $(1 \mathrm{mg} / \mathrm{ml})$ for $15 \mathrm{~min}$. The cells were then mounted in Antifade media, and images were captured using an Olympus BX53 fluorescence microscope (Olympus). The objectives were set at wavelengths of $594 \mathrm{~nm}$ for $\gamma \mathrm{H} 2 \mathrm{AX}$ and $350 \mathrm{~nm}$ for DAPI.

DNA extraction and detection of DNA fragmentation. The DNA ladder assay was performed according to the protocol published previously by our own laboratory. After the cells were treated with ginsenoside $\mathrm{Rg} 3$ and MNNG at concentrations of 50 and $20 \mu \mathrm{M}$, respectively, for $24 \mathrm{~h}$, pellets containing $1 \times 10^{6}$ cells were lysed in lysis buffer $(10 \mathrm{mM}$ Tris-HCl, pH 8.0, 25 mM EDTA, 0.5\% SDS, $100 \mathrm{mM}$ $\mathrm{NaCl}$ and $400 \mathrm{~g} / \mathrm{ml}$ protease $\mathrm{K}$ ) for $120 \mathrm{~min}$ at $56^{\circ} \mathrm{C}$, then treated with $10 \mathrm{mg} / \mathrm{ml}$ RNase A for an additional $50 \mathrm{~min}$ at $37^{\circ} \mathrm{C}$. The lysates were centrifuged $(12,000 \mathrm{x}$ for $30 \mathrm{~min}$ at $4^{\circ} \mathrm{C}$ ), and the supernatant was collected. The fragmented 
DNA was extracted from the supernatant with a neutral phenol:chloroform:isoamyl alcohol mixture (v/v/v, 25:24:1). The DNA pellet was precipitated by adding isopropanol, then washed with $75 \%$ ethanol, and dissolved in Tris-EDTA buffer (10 mM Tris-HCl, 1 mM EDTA, pH 8.0). DNA fragmentation was detected by electrophoresis through an agarose gel, and the bands were stained with ethidium bromide for UV light visualization.

Detection of apoptotic incidence by flow cytometry. Apoptotic incidence was measured using the Annexin V-FITC Apoptosis Detection Kit I (BD Pharmingen) according to the manufacturer's instructions. Briefly, cells were treated with ginsenoside $\mathrm{Rg} 3$ and MNNG at concentrations of 50 and $20 \mu \mathrm{M}$, respectively, for $24 \mathrm{~h}$. Then, cells were washed twice with cold PBS and resuspended in $500 \mu \mathrm{l}$ of binding buffer at a concentration of $1 \times 10^{6}$ cells $/ \mathrm{ml}$. Then, $5 \mu \mathrm{l}$ of Annexin V-FITC solution and $5 \mu \mathrm{l}$ of propidium iodide (PI; $1 \mathrm{mg} / \mathrm{ml}$ ) were added; cells were incubated at $37^{\circ} \mathrm{C}$ for $30 \mathrm{~min}$. The cells were analyzed by flow cytometry within $1 \mathrm{~h}$. Apoptotic cells were counted and represented as a percentage of the total cell count.

Statistical analysis. The data are expressed as the mean values $( \pm$ SEM) of 3 independent experiments. The differences among the treated groups and the negative control were compared by one-way analysis of variance. The Newman-Keuls multiple comparisons test was applied; the significance level was set at $\mathrm{P}<0.05$. All statistical analyses were performed using SPSS 17.0 (SPSS, Inc., Chicago, IL, USA).

\section{Results}

Cytotoxic effects of ginsenoside Rg3. To identify the cytotoxic effect of ginsenoside $\mathrm{Rg} 3$ on human osteosarcoma MG-63, OS732, U-2OS and HOS cell lines and fibroblasts, we initially treated these cells with various concentrations of ginsenoside $\mathrm{Rg} 3$ for $24 \mathrm{~h}$. Cell viability was estimated by MTT assay and trypan blue staining. Ginsenoside Rg3 triggered a concentration-dependent decrease in the viability of MG-63 and U-2OS cells. According to our results, MG-63 and U-2OS cells were the most sensitive to ginsenoside $\operatorname{Rg} 3$ and, thus, the two cell lines were used in the subsequent experiments. Meanwhile, ginsenoside $\operatorname{Rg} 3$ had no effect on the cell viability of the normal human cells (human fibroblasts) (Fig. 1).

Alkaline comet assay for the identification of DNA singlestrand breaks. When subjected to the alkaline comet assay, DNA fragments migrate to form a comet-like image. For the negative control, comet heads contained high-density DNA and exhibited smooth margins and intact nuclei. MG-63 and U-2OS cells accounted for $6 \%$ of those in comet-like formations. In the groups treated with ginsenoside $\mathrm{Rg} 3$, DNA comets exhibited broom-shaped tails. The fluorescence intensity of their heads was weaker than that of the negative control (Fig. 2A). After treatment with ginsenoside Rg3, the percentages of comet-positive MG-63 and U-2OS cells were significantly increased $(\mathrm{P}<0.01)$ at 50,100 and $150 \mathrm{mM}$, when compared to the negative control (Fig. 2B).

The characteristics of MG-63 and U-2OS cells exposed to ginsenoside $\operatorname{Rg} 3$, including mean $( \pm \mathrm{SEM})$ tail length, tail

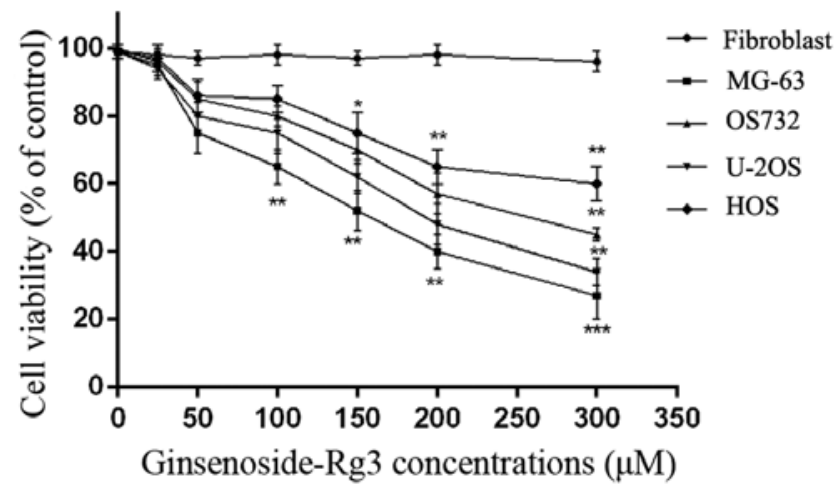

Figure 1. Cytotoxicity of ginsenoside Rg3 in human osteosarcoma MG-63, OS732, U-2OS and HOS cell lines and fibroblasts. Cell viability was determined by MTT assay and expressed as the mean values $( \pm$ SEM) of 3 independent experiments. ${ }^{*} \mathrm{P}<0.05$ and ${ }^{* *} \mathrm{P}<0.01$ represent significant differences relative to the negative controls.

$\mathbf{A}$
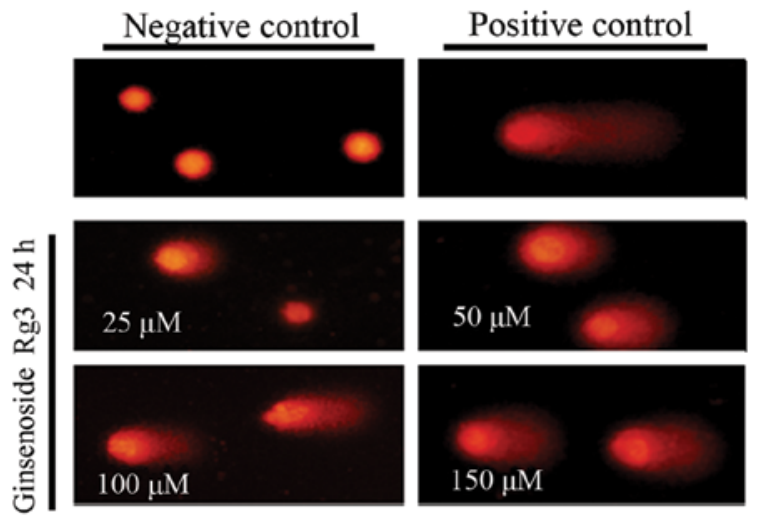

MG-63 cells

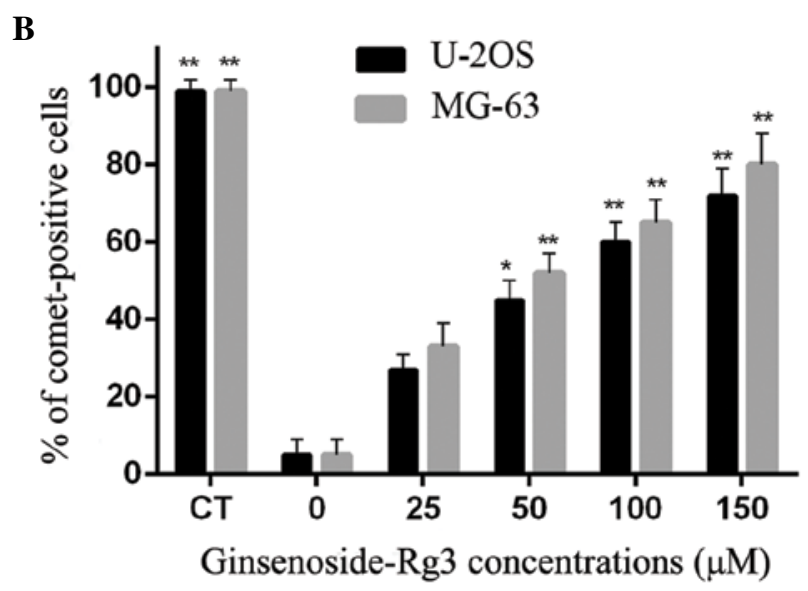

Figure 2. Comet assay evidence of DNA damage (A) as observed on alkaline gel electrophoresis with MG-63 cells (original magnification, x200) (CT a positive control; MNNG, $20 \mathrm{mM}$ ). (B) The percentage of comet-positive cells in the MG-63 and U-2OS cell lines treated with ginsenoside Rg3. Data represent the mean values $\left( \pm\right.$ SEM) of 3 independent experiments. ${ }^{*} \mathrm{P}<0.05$ and ${ }^{* *} \mathrm{P}<0.01$, significantly different relative to the negative control.

DNA and tail moment, are presented in Table I. These results demonstrated that cells exposed to ginsenoside $\mathrm{Rg} 3$ exhibited more severe DNA damage than the negative control samples. Similar trends of DNA damage induced by ginsenoside $\mathrm{Rg} 3$ were noted in the MG-63 and U-2OS cells. 


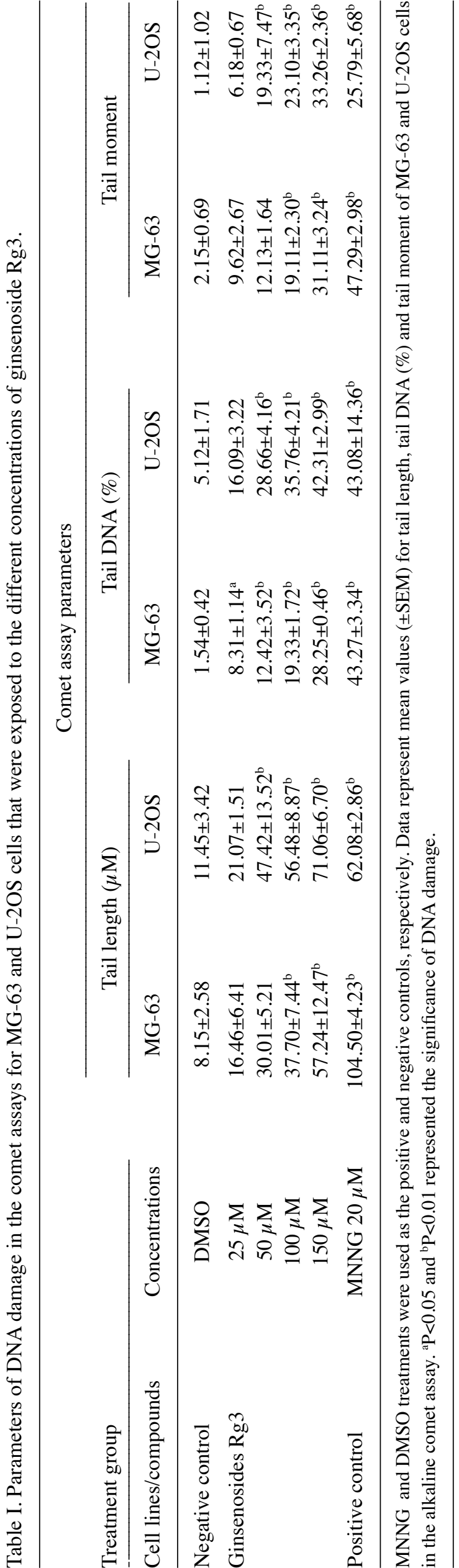

A A Ginsenoside- $\mathrm{Rg} 3$

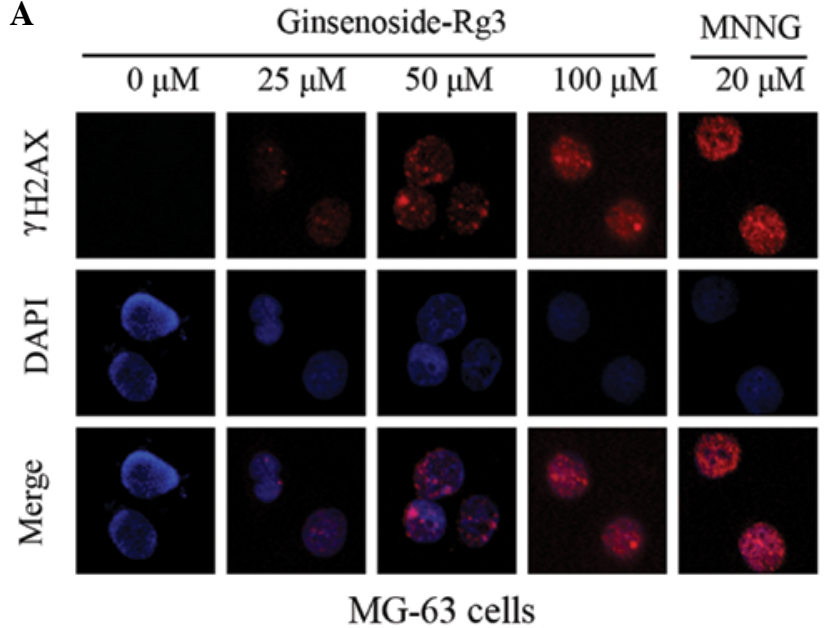

B
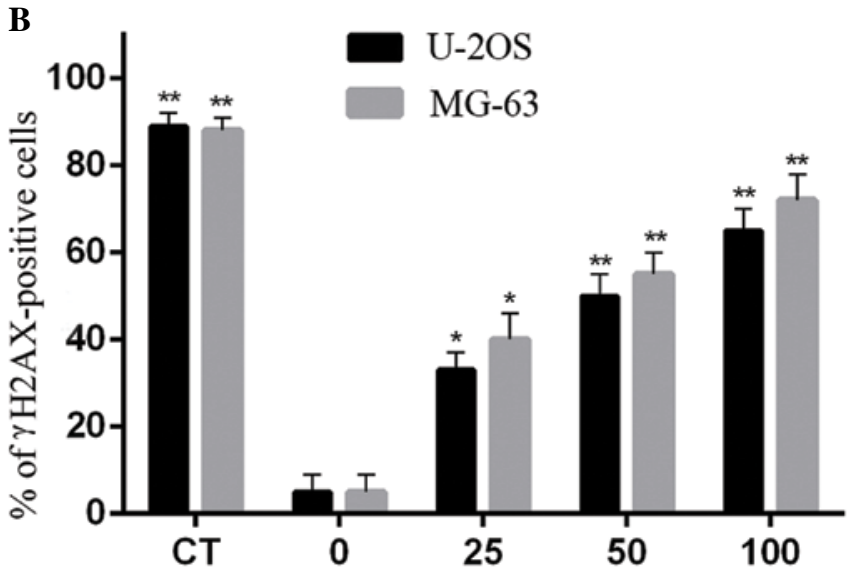

Ginsenoside-Rg3 concentrations $(\mu \mathrm{M})$

Figure 3. DNA double-strand breaks as illustrated by $\gamma \mathrm{H} 2 \mathrm{AX}$ focus formation in MG-63 and U-2OS cells. (A) Representative immunofluorescent images of $\gamma \mathrm{H} 2 \mathrm{AX}$ focus formation in MG-63 cells. The anti- $\gamma \mathrm{H} 2 \mathrm{AX}$ monoclonal antibody was used to detect DNA damage foci immunofluorescence, and DAPI was used for nuclear staining (original magnification, $\mathrm{x} 400$ ) (B) The percentage of $\gamma \mathrm{H} 2 \mathrm{AX}$-positive (foci $\geq 4$ ) MG-63 and U-2OS cells treated with $20 \mathrm{mM}$ MNNG (CT) and 0, 25, 50 and $100 \mathrm{mM}$ ginsenoside Rg3 for $24 \mathrm{~h}$. Data are presented as the mean values $( \pm$ SEM) of 3 independent experiments. ${ }^{*} \mathrm{P}<0.05$ and ${ }^{* * *} \mathrm{P}<0.01$ represent significant differences from the negative control.

$\gamma H 2 A X$ focus staining for DNA double-strand breaks. A threshold of $\geq 4 \gamma \mathrm{H} 2 \mathrm{AX}$ foci per cell was determined as optimal for quantifying the extent of DNA damage (15). Ginsenoside $\operatorname{Rg} 3$ caused a concentration-dependent increase in the formation of $\gamma \mathrm{H} 2 \mathrm{AX}$ foci in MG-63 and U-2OS cells. Representative immunofluorescent images of the phosphorylation of histone $\mathrm{H} 2 \mathrm{AX}$ in $\gamma \mathrm{H} 2 \mathrm{AX}$-stained MG-63 cells are shown in Fig. 3A. Negative-control MG-63 and U-2OS cells had few $\gamma \mathrm{H} 2 \mathrm{AX}$ foci ( $\sim 5 \%$ of cells contained $>4$ foci). All of the treatments with ginsenoside $\mathrm{Rg} 3$ and $\mathrm{MNNG}$ induced focus formation, thereby increasing the percentage of $\gamma \mathrm{H} 2 \mathrm{AX}$ positive cells. Ginsenoside Rg3 and MNNG both exhibited distinct concentration-dependent effects $(\mathrm{P}<0.01)$ on $\gamma \mathrm{H} 2 \mathrm{AX}$ focus formation in MG-63 and U-2OS cells (Fig. 3B).

Effects of ginsenoside Rg3 on MNNG-induced DNA damage in human fibroblasts. Ginsenoside Rg3 was reported to have 
A

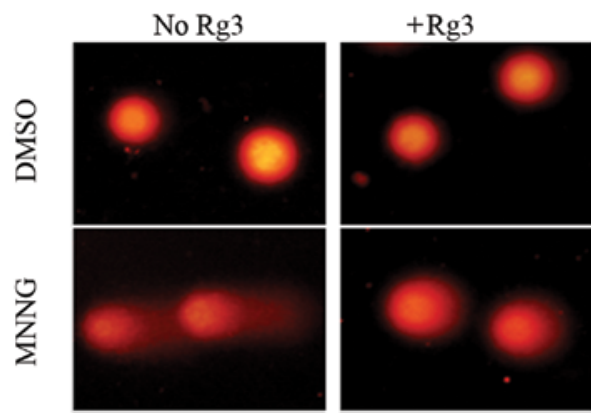

Fibroblasts

B

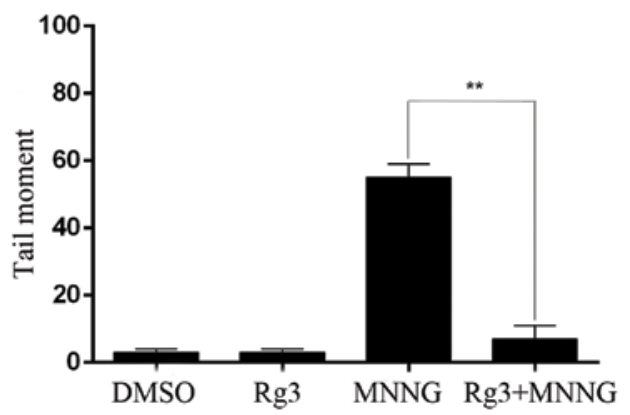

Figure 4. Protective effect of ginsenoside Rg3 on MNNG-induced DNA damage as illustrated by an alkaline comet assay in human fibroblasts. Cells were cotreated with ginsenoside Rg3 (50 mM) and MNNG (20 mM) for $24 \mathrm{~h}$. (A) Representative images of comets (original magnification, $x 200$ ). (B) The results represent mean values $( \pm \mathrm{SEM})$ of the tail moment as measured for 200 comets. ${ }^{* *} \mathrm{P}<0.01$ represents a significant difference.

a cytoprotective effect (9). We, therefore, sought to investigate the ability of ginsenoside $\mathrm{Rg} 3$ to protect human fibroblasts against MNNG-induced DNA damage. The number of MNNG-induced DNA single-strand breaks was measured using the alkaline comet assay. The extent of DNA damage was significantly greater in the $\mathrm{MNNG}$ treatment group as compared to the DMSO treatment group. In the cells pretreated with $50 \mathrm{mM}$ ginsenoside $\mathrm{Rg} 3$ in combination with MNNG as opposed to MNNG alone, the tail moments were significantly decreased. Treatment with ginsenoside Rg3 alone did not induce any genotoxicity in the human fibroblasts (Fig. 4). The cytoprotective effect was further confirmed by staining $\gamma \mathrm{H} 2 \mathrm{AX}$ foci. The percentage of $\gamma \mathrm{H} 2 \mathrm{AX}$-positive cells in the DMSO and MNNG treatment group was 5.3 and $86.9 \%$, respectively. Ginsenoside $\mathrm{Rg} 3$ was effective in reducing the proportion of cells with MNNG-induced DNA strand breakage from 86.9 to $28.3 \%$ (Fig. 5).

Effects of ginsenoside Rg3 on MNNG-induced apoptosis in human fibroblasts. The rate of cell apoptosis was determined by flow cytometry. Representative graphs of cells treated with ginsenoside Rg3 and MNNG for $24 \mathrm{~h}$ after double staining with Annexin V-FITC and PI are shown in Fig. 6A. The rate of apoptosis in the MNNG-treated cells was $44.7 \pm 2.0 \%$. When cells were treated with ginsenoside $\operatorname{Rg} 3(50 \mathrm{mM})$ prior to MNNG administration, the number of apoptotic human fibroblasts as measured $24 \mathrm{~h}$ after pre-treatment was significantly decreased $(12.3 \pm 2.1 \%$ ) (Fig. 6B). Cells in the DMSO and ginsenoside $\mathrm{Rg} 3$ groups showed low rates of apoptosis. MNNG induced a ladder-like pattern on agarose gel (Fig. 6C).
A

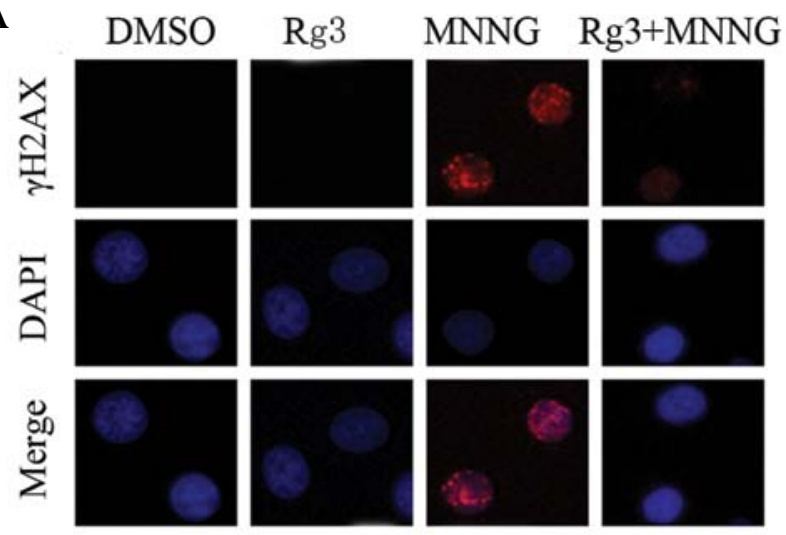

B

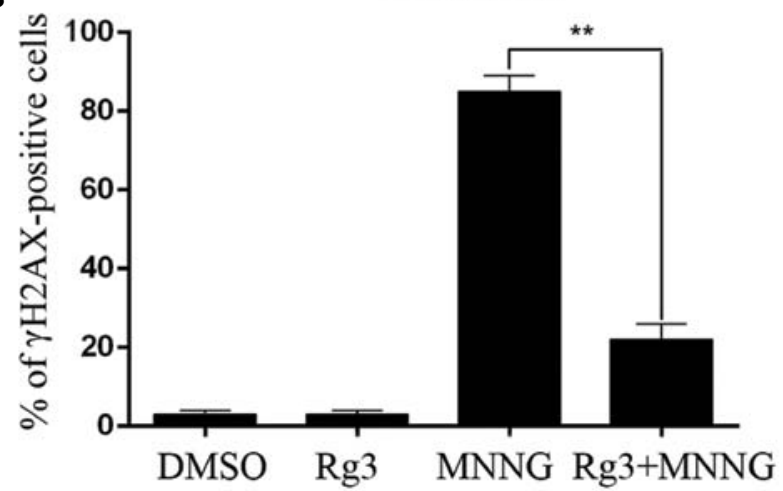

Figure 5. Protective effect of ginsenoside Rg3 on MNNG-induced doublestrand breaks was illustrated by $\gamma \mathrm{H} 2 \mathrm{AX}$ focus formation in human fibroblasts. Cells were cotreated with ginsenoside $\operatorname{Rg} 3(50 \mathrm{mM})$ and MNNG $(20 \mathrm{mM})$ for $24 \mathrm{~h}$. (A) Images of $\gamma \mathrm{H} 2 \mathrm{AX}$ foci. The anti- $\gamma \mathrm{H} 2 \mathrm{AX}$ monoclonal antibody was used to detect DNA damage foci immunofluorescence, and DAPI was used for nuclear staining (original magnification, $x 400$ ). (B) The percentage of $\gamma \mathrm{H} 2 \mathrm{AX}$-positive (foci $\geq 4$ ) cells. Data are presented as the mean values $( \pm \mathrm{SEM})$ of 3 independent experiments. ${ }^{* *} \mathrm{P}<0.01$ represents a significant difference.

Cotreatment with ginsenoside $\operatorname{Rg} 3(50 \mathrm{mM})$ induced minimal DNA fragmentation in human fibroblasts. These results suggest that ginsenoside Rg3 alleviates MNNG-induced cytotoxicity.

\section{Discussion}

Ginseng, an ancient and famous herbal drug in traditional Chinese medicine, has been used in Chinese folklore for more than 5,000 years. The most important pharmacological components in ginseng are ginsenosides. Ginsenoside Rg3 is the primary ginsenoside in ginseng. The compound can enhance immunity (16), protect against the effects of free radicals (17), suppress the invasion and metastasis of various carcinoma cells (18) and inhibit tumor angiogenesis (19).

The cytoprotective effect of ginsenosides has been demonstrated in various studies. Ginsenoside $\operatorname{Rg} 3$ was found to protect against DNA damage and cell apoptosis by reducing oxidative stress (10), while ginsenoside $20(S)$-protopanaxatriol protected endothelial cells against oxidative stress through the regulation of intracellular redox status (20).

Osteosarcoma is the most common type of bone cancer, and the sixth most common type of cancer in children. Before any major surgery to remove the tumor is undertaken, 


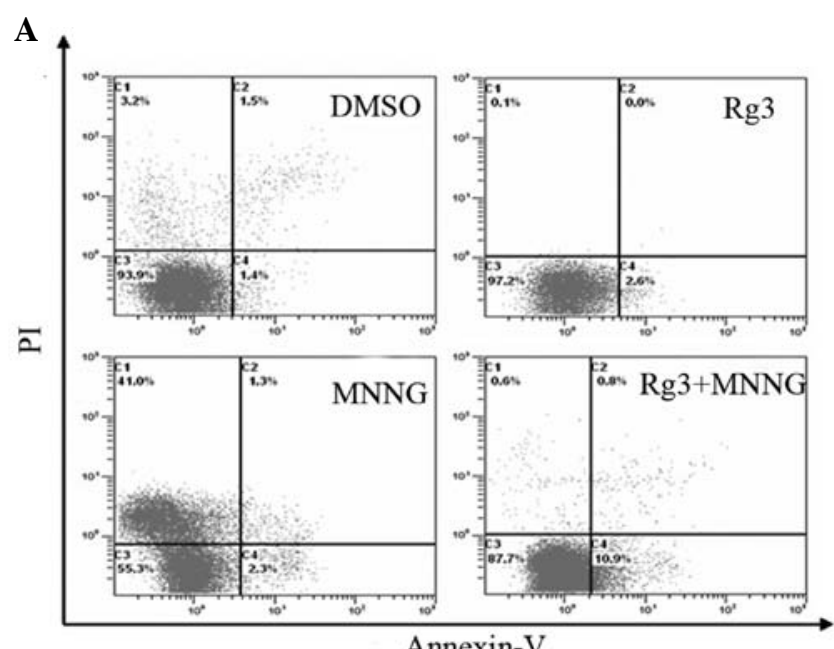

Annexin-V
B

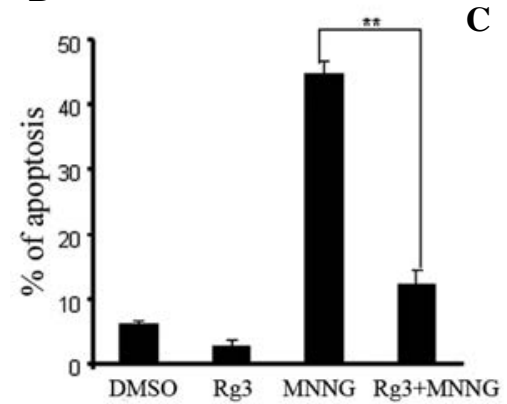

$\mathrm{Rg} 3+$

M DMSO Rg3 MNNG MNNG

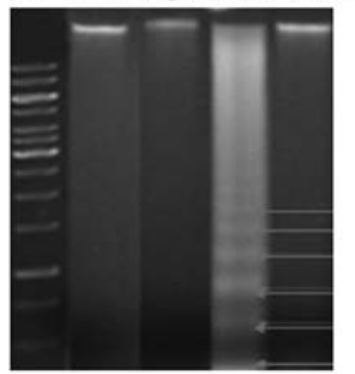

Figure 6. Protective effect of ginsenoside Rg3 on MNNG-induced apoptosis in human fibroblasts. (A) Flow cytometric analysis of apoptosis using Annexin V and PI. (B) The apoptotic rate of human fibroblasts treated with ginsenoside Rg3 (50 mM) and MNNG (20 mM) for $24 \mathrm{~h}$. Data are presented as the mean values $\left( \pm\right.$ SEM) of 3 independent experiments. ${ }^{* *} \mathrm{P}<0.01$ repre sents a significant difference. (C) DNA fragmentation on an agarose gel DNA isolated from renal tissues of experimental rats was loaded onto $1 \%$ (w/v) agarose gels. M, marker (1-kb DNA ladder).

chemotherapy is usually administered to shrink the tumor and facilitate surgery. It may also kill any cancer cells that have spread to other areas of the body. Conventional chemotherapeutic agents such as cyclophosphamide are often toxic not only to tumor cells but also to normal cells, limiting their therapeutic use in clinics. Natural products are potentially valuable sources for the development of new anticancer drugs due to their weak side-effects (21). However, no previous report has examined whether ginsenoside $\mathrm{Rg} 3$ can influence human osteosarcoma cell activity or induce DNA damage. Here, we confirmed that ginsenoside $\mathrm{Rg} 3$ inhibits cell proliferation in human osteosarcoma cells, particularly in MG-63 and U-2OS cells.

The alkaline comet assay is a form of single-cell gel electrophoresis that can be used to detect DNA damage (22). $\gamma \mathrm{H} 2 \mathrm{AX}$ focus formation can be used in this capacity as well. The alkaline comet assay is a sensitive fluorescence microscope-based method that can be used to detect DNA damage (22) caused primarily by DNA strand breaks, DNA adduct formations, and DNA-DNA and DNA-protein cross-links (23). Moreover, the formation of DNA double-strand breaks could induce the formation of $\gamma \mathrm{H} 2 \mathrm{AX}$ aggregations in nuclei. $\gamma \mathrm{H} 2 \mathrm{AX}$ focus formation has been suggested as a sensitive way to detect DNA double-strand breaks (24). The phosphorylation of histone
H2AX can be induced by replication stress (25), ionizing radiation (26), exogenous stress (27) and drugs that cause DNA damage (28). A threshold of $\geq 4 \gamma \mathrm{H} 2 \mathrm{AX}$ foci per cell is optimal for determining the severity of DNA damage (15). We, therefore, employed the alkaline comet assay and measurements of the formation of $\gamma \mathrm{H} 2 \mathrm{AX}$ foci to detect DNA damage induced by ginsenoside Rg3 in MG-63 and U-2OS cells. Our results demonstrated a concentration-dependent increase in the size of comet tails with a concomitant reduction in head size. The images of representative comets clearly demonstrated the amount of broken DNA liberated from the heads of the comets during electrophoresis following treatment with increasing ginsenoside $\mathrm{Rg} 3$ concentrations. A threshold of $\geq 4$ $\gamma \mathrm{H} 2 \mathrm{AX}$ foci per cell was optimal for measuring the extent of DNA damage. This helped in efforts to identify the cellular DNA damage caused by ginsenoside Rg3. Treatment with ginsenoside $\mathrm{Rg} 3$ demonstrated an increase in the number of $\gamma \mathrm{H} 2 \mathrm{AX}$-positive cells; approximately half of these cells were positive following treatment at $25 \mathrm{mM}$, with almost $76 \%$ positive cells noted following treatment with a $100 \mathrm{mM}$ solution (Fig. 3). In the present study, we demonstrated that the presence of $\gamma \mathrm{H} 2 \mathrm{AX}$ foci may be indicative of DNA strand breaks, which can be confirmed by comet assay. These results are in concordance with those reported in another study, showing that ginsenoside $\operatorname{Rg} 3$ mediates antiproliferative and apoptotic activity in cancer cells (29).

Previous research has shown that MNNG can induce the apoptosis of fibroblasts (14). Flow cytometry and the DNA ladder assay were used to detect the ability of ginsenoside $\mathrm{Rg} 3$ to protect against MNNG-induced apoptosis in human fibroblasts. The ability of ginsenoside $\mathrm{Rg} 3$ to protect against MNNG-induced DNA damage was also evaluated using alkaline comet assay and $\gamma \mathrm{H} 2 \mathrm{AX}$ focus formation. The results obtained showed that cotreatment with ginsenoside $\operatorname{Rg} 3$ significantly decreased MNNG-induced DNA damage and apoptosis.

These results were consistent with those of other studies. For example, red ginseng protected cells from Helicobacter pylori-induced DNA damage and cytotoxicity (30). Poon et al (9) showed that ginsenoside $20(S)-\operatorname{Rg} 3$ can significantly decrease BaP-induced DNA damage using the TUNEL and comet assays in human dermal fibroblasts. Ginsenoside 20(S)-Rg3 protected against cyclophosphamide-induced DNA damage and cell apoptosis in mouse bone marrow cells and peripheral lymphocyte cells (10). Ginseng was also found to inhibit micronucleus formation and chromosomal instability $(31,32)$.

We found that ginsenoside $\operatorname{Rg} 3$ protected against the effects of exposure to environmental contaminants. However, further in vivo studies are required to elucidate the cytoprotective effects of ginsenoside $\mathrm{Rg} 3$ in cells vulnerable to the genotoxic effects of environmental contaminants. Zhou and Elledge (33) indicated that organisms respond to DNA damage (DNA strand breaks) by activating a complex damage response pathway. This pathway regulates known responses such as cell cycle arrest and apoptosis. Previous reports also demonstrated that ginsenoside $\mathrm{Rg} 3$ treatment increases the amount of time spent by a cell in the $\mathrm{G}_{2} / \mathrm{M}$ phase, and therefore, the likelihood that agents designed to damage DNA will in fact trigger apoptosis (34). 
There are some limitations to the present study. It is not clear whether the induction of cell cycle arrest and apoptosis were directly related to genotoxic effects. Further studies will be necessary to elucidate the underlying mechanism.

In conclusion, ginsenoside $\mathrm{Rg} 3$ is a strong genotoxic agent that induces DNA damage in human osteosarcoma cells. Moreover, ginsenoside Rg3 protected normal human fibroblasts against the DNA damage and apoptosis induced by MNNG treatment in vitro. Therefore, ginsenoside $\mathrm{Rg} 3$ may represent a potential chemopreventive agent for the treatment of patients with osteosarcomas.

\section{Acknowledgements}

This study was supported by the National Natural Science Foundation of China (81302340).

\section{References}

1. Mirabello L, Troisi RJ and Savage SA: Osteosarcoma incidence and survival rates from 1973 to 2004: data from the Surveillance, Epidemiology, and End Results Program. Cancer 115: 1531-1543, 2009.

2. Bacci G, Balladelli A, Palmerini E, et al: Neoadjuvant chemotherapy for osteosarcoma of the extremities in preadolescent patients: the Rizzoli Institute experience. J Pediatr Hematol Oncol 30: 908-912, 2008.

3. Hemmerly TE: A ginseng farm in Lawrence County Tennessee. Econ Bot 31: 160-162, 1977.

4. Toh DF, Patel DN, Chan EC, Teo A, Neo SY and Koh HL: Anti-proliferative effects of raw and steamed extracts of Panax notoginseng and its ginsenoside constituents on human liver cancer cells. Chin Med 6: 4-9, 2011.

5. Molnar J, Szabo D, Pusztai R, et al: Membrane associated antitumor effects of crocine-, ginsenoside- and cannabinoid derivates. Anticancer Res 20: 861-867, 2000.

6. Li B, Zhao J, Wang CZ, et al: Ginsenoside Rh2 induces apoptosis and paraptosis-like cell death in colorectal cancer cells through activation of p53. Cancer Lett 301: 185-192, 2011.

7. Chen J, Peng H, Ou-Yang X and He X: Research on the antitumor effect of ginsenoside Rg3 in B16 melanoma cells. Melanoma Res 18: 322-329, 2008

8. Nag SA, Qin JJ, Wang W, Wang MH, Wang H and Zhang R: Ginsenosides as anticancer agents: in vitro and in vivo activities, structure-activity relationships, and molecular mechanisms of action. Front Pharmacol 3: 25, 2012.

9. Poon PY, Kwok HH, Yue PY, et al: Cytoprotective effect of $20 S-\operatorname{Rg} 3$ on benzo $[a]$ pyrene-induced DNA damage. Drug Metab Dispos 40: 120-129, 2012.

10. Zhang QH, Wu CF, Duan L and Yang JY: Protective effects of ginsenoside $\mathrm{Rg}_{3}$ against cyclophosphamide-induced DNA damage and cell apoptosis in mice. Arch Toxicol 82: 117-123 2008.

11. Kim TH, Lee YS, Cho CK, Park S, Choi SY and Yool SY: Protective effect of ginseng on radiation-induced DNA double strand breaks and repair in murine lymphocytes. Cancer Biother Radiopharm 11: 267-272, 1996.

12. Liu JW, Yang F, Zhang Y and Li JY: Studies on the cell immunosuppressive mechanism of Oridonin from Isodon serra. Int Immunopharmacol 7: 945-954, 2007.

13. Calderon-Segura ME, Gomez-Arroyo S, Molina-Alvarez B, et al: Metabolic activation of herbicide products by Vicia faba detected in human peripheral lymphocytes using alkaline single cell gel electrophoresis. Toxicol In Vitro 21: 1143-1154, 2007.
14. Izumchenko E, Saydi J and Brown KD: Exonuclease 1 (Exo1) is required for activating response to $\mathrm{S}_{\mathrm{N}} 1$ DNA methylating agents. DNA Repair 11: 951-964, 2012.

15. Sokolov MV, Smilenov LB, Hall EJ, Panyutin IG, Bonner WM and Sedelnikova OA: Ionizing radiation induces DNA doublestrand breaks in bystander primary human fibroblasts. Oncogene 24: 7257-7265, 2005.

16. Bae EA, Han MJ, Shin YW and Kim DH: Inhibitory effects of Korean red ginseng and its genuine constituents ginsenosides $\mathrm{Rg} 3, \mathrm{Rf}$, and $\mathrm{Rh} 2$ in mouse passive cutaneous anaphylaxis reaction and contact dermatitis models. Biol Pharm Bull 29: 1862-1867, 2006.

17. Tian J, Fu F, Geng M, et al: Neuroprotective effect of 20(S)-ginsenoside $\operatorname{Rg} 3$ on cerebral ischemia in rats. Neurosci Lett 374: 92-97, 2005.

18. Iishi $\mathrm{H}$, Tatsuta M, Baba M, et al: Inhibition by ginsenoside Rg3 of bombesin-enhanced peritoneal metastasis of intestinal adenocarcinomas induced by azoxymethane in Wistar rats. Clin Exp Metastasis 15: 603-611, 1997.

19. Shinkai K, Akedo H, Mukai M, et al: Inhibition of in vitro tumor cell invasion by ginsenoside Rg3. Jpn J Cancer Res 87: 357-362, 1996.

20. Kwok HH, Ng WY, Yang MS, Mak NK, Wong RN and Yue PY: The ginsenoside protopanaxatriol protects endothelial cells from hydrogen peroxide-induced cell injury and cell death by modulating intracellular redox status. Free Radic Biol Med 48: 437-445, 2010.

21. Mann J: Natural products in cancer chemotherapy: past, present and future. Nat Rev Cancer 2: 143-148, 2002.

22. Kassie F, Parzefall W and Knasmuller S: Single cell gel electrophoresis assay: a new technique for human biomonitoring studies. Mutat Res 463: 13-31, 2000.

23. Cotelle S and Ferard JF: Comet assay in genetic ecotoxicology: a review. Environ Mol Mutagen 34: 246-255, 1999.

24. Yu Y, Zhu W, Diao H, Zhou C, Chen FF and Yang J: A comparative study of using comet assay and $\gamma \mathrm{H} 2 \mathrm{AX}$ foci formation in the detection of $N$-methyl- $N$ '-nitro- $N$-nitrosoguanidine-induced DNA damage. Toxicol In Vitro 20: 959-965, 2006

25. Ward IM, Minn K and Chen J: UV-induced ataxia-telangiectasiamutated and Rad3-related (ATR) activation requires replication stress. J Biol Chem 279: 9677-9680, 2004.

26. Rogakou EP, Pilch DR, Orr AH, Ivanova VS and Bonner WM: DNA double-stranded breaks induce histone H2AX phosphorylation on serine 139. J Biol Chem 273: 5858-5868, 1998.

27. Tanaka T, Huang X, Halicka HD, et al: Cytometry of ATM activation and histone $\mathrm{H} 2 \mathrm{AX}$ phosphorylation to estimate extent of DNA damage induced by exogenous agents. Cytometry A 71: 648-661, 2007

28. Banáth JP and Olive PL: Expression of phosphorylated histone $\mathrm{H} 2 \mathrm{AX}$ as a surrogate of cell killing by drugs that create DNA double-strand breaks. Cancer Res 63: 4347-4350, 2003.

29. Wang CZ, Aung HH, Ni M, et al: Red American ginseng: ginsenoside constituents and antiproliferative activities of heat-processed Panax quinquefolius roots. Planta Med 73: 669-674, 2007.

30. Park S, Yeo M, Jin JH, et al: Rescue of Helicobacter pyloriinduced cytotoxicity by red ginseng. Dig Dis Sci 50: 1218-1227, 2005.

31. Ivanova T, Han Y, Son HJ, Yun YS and Song JY: Antimutagenic effect of polysaccharide ginsan extracted from Panax ginseng. Food Chem Toxicol 44: 517-521, 2006

32. Panwar M, Samarth R, Kumar M, Yoon WJ and Kumar A: Inhibition of benzo(a)pyrene induced lung adenoma by Panax ginseng extract, EFLA400, in Swiss albino mice. Biol Pharm Bull 28: 2063-2067, 2005.

33. Zhou BB and Elledge SJ: The DNA damage response: putting checkpoints in perspective. Nature 408: 433-439, 2000.

34. Park HM, Kim SJ, Kim JS and Kang HS: Reactive oxygen species mediated ginsenoside Rg3- and Rh2-induced apoptosis in hepatoma cells through mitochondrial signaling pathways. Food Chem Toxicol 50: 2736-2741, 2012. 